\title{
Depigmented lesions of pityriasis versicolor: A diagnostic dilemma with review of literature
}

\author{
Tejinder Kaur', Daljit Singh', Suresh K. Malhotra', Arashbir Kaur² \\ ${ }^{1}$ Department of Dermatology Venereology and Leprology, Government Medical College, Amritsar, Punjab, India, \\ ${ }^{2}$ Department of Medicine, Government Medical College, Patiala, Punjab, India
}

Corresponding author: Dr. Daljit Singh, E-mail: daljit919@gmail.com

\begin{abstract}
Pityriasis versicolor is a superficial mycosis affecting the skin. It is caused by malassezia species of fungi. Common sites of involvement are chest, neck and shoulders. We report a rare case of pityriasis versicolor affecting both arms and dorsum of both hands but sparing the commonly involved sites and masquerading vitiligo.
\end{abstract}

Key words: Pityriasis versicolor; Acral; Spaghetti and meat ball appearance; Vitiligo

\section{INTRODUCTION}

Pityriasis versicolor (PV) is a common disorder known by various names like PV, Dermatomycosis perforatia, Tinea flava, Liver spots or Achromia parasitica. Pityriasis versicolor is a superficial mycosis, affecting the superficial layer of statum corneum. It is characterized by hypopigmented, hyperpigmented, leucodermal or erythematous scaly macules or patches primarily on trunk and proximal extremities. It is caused by Malassezia furfur which was first recognized as a fungal disease in 1846 by Eichstedt and demonstrated in the scales of Tinea versicolor by Robin in 1853 [1].Here we present a case of PV in which the lesions were localized only to the upper limbs and hypopigmentation was so marked that they closely resembled vitiligo.

\section{CASE REPORT}

A 25 year old male, shopkeeper by profession presented with asymptomatic almost depigmented patches on both upper limbs since 6 months. On examination, bilaterally symmetrical depigmented patches of size $7 \mathrm{cmX} 31 \mathrm{~cm}$ with well defined irregular margins were present on flexor aspect of bilateral upper limbs (Fig. 1). Depigmented to hypopigmented macules and patches of size ranging from $0.5 \mathrm{cmX} 0.5 \mathrm{~cm}$ to $1 \mathrm{cmXl} \mathrm{cm}$ were present on dorsum of both hands (Fig. 2). Some of the macules were coalesceing to form patches with polycyclic margins. These lesions were not associated with any obvious scaling, however mild scaling could be observed on scraping the lesions. Hair, nails and mucus membranes were normal. Based on clinical findings differential diagnosis of Vitiligo and PV was kept. On Wood's lamp examination the yellow hue of the lesions indicated the lesions to be of PV.

$\mathrm{KOH}$ examination revealed hyphae and spores giving the characteristic 'spaghetti and meat ball' appearance thus confirming the diagnosis of PV. The patient was not willing for biopsy. All other investigations like $\mathrm{Hb}, \mathrm{TLC}, \mathrm{DLC}, \mathrm{FBS}$, Renal and liver function tests were within normal limits. The patient was put on Fluconazole $400 \mathrm{mg}$ stat and miconazole cream for local application. The lesions started improving after 2 weeks of follow up.

\section{DISCUSSION}

In 1951, Gordon isolated and characterized the organism M.furfur renamed it Pityrosporum orbiculare [1,2]. But now it has been recognized and accepted that M. furfur is the correct name and other are synonyms. M. furfur is a component of the normal skin flora in more than

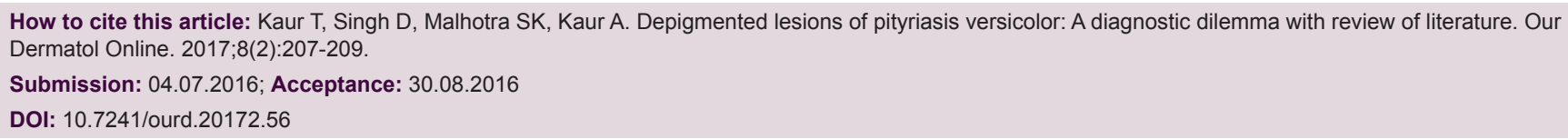




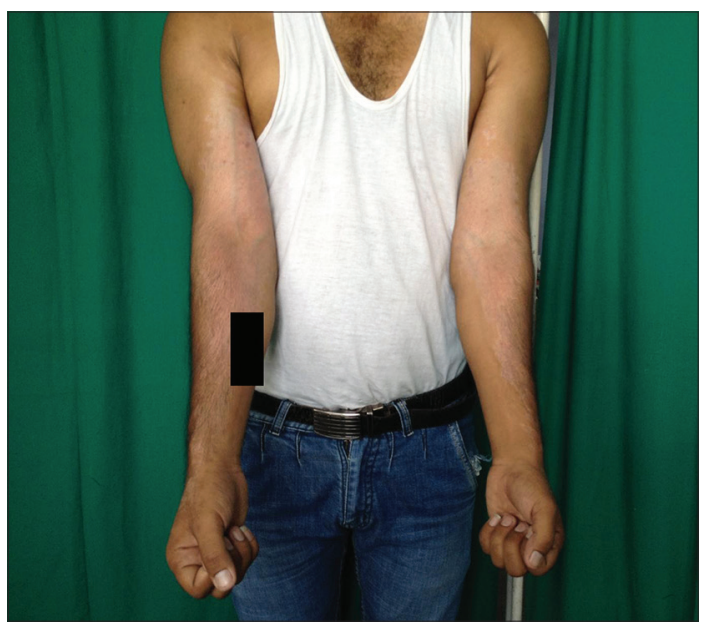

Figure 1: Bilaterally symmetrical depigmented patches of size $7 \mathrm{~cm} \times 31 \mathrm{~cm}$ with well defined irregular margins were present on flexor aspect of bilateral upper limbs.

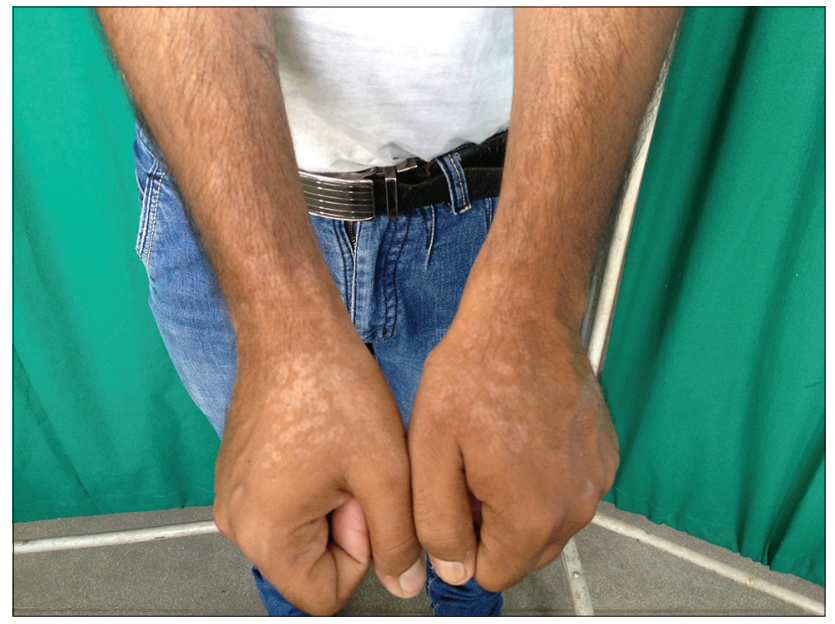

Figure 2: Depigmented to hypopigmented macules and patches of size ranging from $0.5 \mathrm{~cm} \times 0.5 \mathrm{~cm}$ to $1 \mathrm{~cm} \times 1 \mathrm{~cm}$ present on dorsum of both hands.

$90 \%$ of adults living in tropical areas. It was thought to be the sole causative agent of PV. But recently genetic analysis have indicated 12 separate species of lipophilic yeasts to be the causative agents of PV, which are M. sympodialis, M. globosa, M. restricta, M. slooffiae, M. furfur, M. obtuse, and the recently described M. dermatis, M. japonica, M. yamotoensis, M. nana, M. caprae and M. equine.

Etiopathogenesis involves the conversion of yeast form to its mycelial form due to certain predisposing factors. These factors can be classified as exogenous and endogenous. The exogenous factors include heat and moisture (wearing synthetic garments in humid environment), occlusion and altered PH range. On the other hand, endogenous factors incriminated are seborrheic dermatitis, Cushings syndrome, immunosuppressive treatment, malnutrition, hyperhidrosis and rarely hereditary factors [3]. PV is most prevalent in early adulthood when the sebaceous glands are active and in individuals who sweat more. The most common site of involvement being chest, neck, shoulder abdomen and sometimes face [1]. However in tropical country like India with high humidity and high temperature uncommon sites like forearms can also be involved. Various other atypical presentations have been reported like atrophying Pityriasis Versicolor [4], involvement of face and lower limbs.

The colour of the lesions varies from white to brown. The pathogenesis of these pigmentary variations has not been clearly established. Hyperpigmentation has been explained by the abnormally large melanosomes, a thick stratum corneum and a hyperemic inflammatory response [1]. While hypopigmentation has been explained by the damage to melanocytes and by inhibition of tyrosinase enzyme by dicarboxylic acids produced by Malassezia furfur; by reduction in number, size, and aggregation of melanosomes in melanocytes and surrounding keratinocytes; and by blocking the ultraviolet light by lipid like material accumulation in stratum corneum. The depigmentation in PV may vary from hypopigmentation to depigmentation thus making Vitiligo, Pityriais alba, seborrhoeic dermatitis and indeterminate leprosy close differentials. As in our case the complete loss of pigment, asymptomatic lesions, minimal scaling, and atypical site of lesions i.e forearms and dorsa of hands made vitiligo also a likely diagnosis. However high clinical suspicion and yellowish hue on woods lamp helped us to think on the lines of PV which was confirmed by examining skin scrapings, giving the characteristic 'spaghetti and meat ball' appearance.

There are numerous ways of treating PV topically as well as systemically. Selenium sulfide shampoo is considered to be the conventional first-line therapy at this time. However, selenium sulfide can be irritating to the skin, often resulting in local discomfort and pruritus [5]. Other topical therapies include propylene glycol, ketoconazole shampoo, zinc pyrithione shampoo, ciclopirox olamine, bifonazole, terbinafine solution, salicylic acid and sulfur soap baths, tioconazole, clotrimazole, griseofulvin, and benzoyl peroxide. Oral treatment in the form of oral fluconazole, a bistriazole with broad spectrum of activity, offer an effective and easily administered treatment [6].

However the hypopigmentation may persist even after effective treatment of PV, so tacrolimus is being used to 


\section{www.odermatol.com}

treat the residual hypopigmentation [7]. Besides all the therapies it is advisable to counsel and treat the patient for hyperhydrosis and other predisposing factors. As in tropical countries like ours synthetic garments, which are less likely to absorb sweat could be the precipitating factor in humid environment or rainy season.

The case is being reported for its atypical presentation

\section{Consent}

The examination of the patient was conducted according to the Declaration of Helsinki principles.

\section{REFERENCES}

1. Hussein AAA. Clinical and Pigmentary Variation of Pityriasis Versicolor in Al-Muthana Government's Patients. Med J Babylon. 2014;7:383-8.
2. Akaberi AA, Amini SS, Hajihosseini H. An Unusual Form of Tinea Versicolor: A Case Report. Iran J Dermatol. 2009;12:S30-1.

3. Hay RJ Ashbee HR. Mycology In: Burns T, Breathnach S, Cox N, Griffiths C (eds.) Rook's Textbook of Dermatology. 8th ed. WileyBlackwell; 2010.p36.10

4. Cullingham K, Hull PR. Atrophying pityriasis versicolor. CMAJ. 2014;10:186.

5. Hull CA, Johnson SM. A Double-Blind Comparative Study of Sodium Sulfacetamide Lotion 10\% Versus Selenium Sulfide Lotion $2.5 \%$ in the Treatment of Pityriasis (Tinea) Versicolor Cheryl A. Cutis. 2004;73:425-9.

6. Sankara Rao IV, Rajashekhar N. Oral fluconazole in tinea versicolor. Indian J Dermatol Venereol Leprol. 1997;63:166-7.

7. Last-Sugita T, Tajima M, Ito T, Saito M, Tsuboi R, Nishikawa A. Antifungal Activities of Tacrolimus and Azole Agents against the Eleven Currently Accepted Malassezia Species. J Clin Microbiol. 2005:43;2824-9.

Copyright by Tejinder Kaur, et al. This is an open access article distributed under the terms of the Creative Commons Attribution License, which permits unrestricted use, distribution, and reproduction in any medium, provided the original author and source are credited.

Source of Support: Nil, Conflict of Interest: None declared. 